Published in final edited form as:

Clin Genet. 2012 April ; 81(4): 303-311. doi:10.1111/j.1399-0004.2011.01809.x.

\title{
Epigenetic modifications in cancer
}

\author{
R Kanwal ${ }^{\mathrm{a}}$ and S Gupta ${ }^{\mathrm{a}, \mathrm{b}, \mathrm{c}}$ \\ aDepartment of Urology, Case Western Reserve University, Cleveland, $\mathrm{OH}, \mathrm{USA}$ \\ bDepartment of Urology, University Hospitals Case Medical Center, Cleveland, OH, USA \\ 'Department of Urology, Case Comprehensive Cancer Center, Cleveland, OH, USA
}

\begin{abstract}
Cancer initiation and progression is controlled by both genetic and epigenetic events. The complexity of carcinogenesis cannot be accounted for by genetic alterations alone but also involves epigenetic changes. Epigenetics refers to the study of mechanisms that alter gene expression without altering the primary DNA sequence. Epigenetic mechanisms are heritable and reversible, and include changes in DNA methylation, histone modifications and small noncoding microRNAs (miRNA). Disruption of epigenetic processes can lead to altered gene function and malignant cellular transformation. Aberrant epigenetic modifications probably occur at a very early stage in neoplastic development, and they are widely described as essential players in cancer progression. Recent advances in epigenetics offer a better understanding of the underlying mechanism(s) of carcinogenesis and provide insight into the discovery of putative cancer biomarkers for early detection, disease monitoring, prognosis, and risk assessment. In this review, we summarize the current literature on epigenetic changes causing genetic alterations that are thought to contribute to cancer, and discuss the potential impact of epigenetics future research.
\end{abstract}

\section{Keywords}

cancer; DNA methylation; epigenetics; histone modification; microRNA

Cancer, initially recognized as a genetic disease, is now known to involve epigenetic abnormalities along with genetic alterations. It is becoming clear that microenvironmentmediated epigenetic perturbations play an important roles in the development of neoplasia (1). Epigenetics refers to the study of heritable changes in gene expression that occur without a change in DNA sequence which are sufficiently powerful to regulate the dynamics of gene expression (2). The key processes responsible for epigenetic regulation are DNA methylation, histone modifications and posttran-scriptional gene regulation by noncoding RNA commonly referred as microRNAs (3). These mechanisms are critical components in the normal development and growth of cells and their modifications contribute to neoplastic phenotypes (4).

Corresponding author: Sanjay Gupta, PhD, Department of Urology, Case Western Reserve University, University Hospitals Case Medical Center, 10900 Euclid Avenue, Cleveland, Ohio 44106, USA., Tel.: (216) 368 6162; fax: (216) 3680213 ;

sanjay.gupta@case.edu.

Conflict of interest

Nothing to declare. 


\section{DNA methylation}

In eukaryotes, methylation is characterized by epigenetic DNA modifications which play an important role in maintenance of genome integrity, genomic imprinting, transcriptional regulation, and developmental processes (5). DNA methylation usually takes place at the $5^{\prime}$ position of the cytosine ring within $\mathrm{CpG}$ dinucleotides, and its consequence is the silencing of genes and noncoding genomic regions. The modification at 5-methyl cytosine is catalyzed by enzyme DNA methyltransferases (DNMTs) (6). There are three main DNMTs: DNMT1, which maintains the existing methylation patterns following DNA replication, and DNMT3A and DNMT3B, de novo enzymes that target unmethylated CpGs to initiate methylation and are highly expressed during embryogenesis and minimally expressed in adult tissues (7). Another family member is DNMT-3L that lacks intrinsic methyltransferase activity; it interacts with DNMT3a and 3b to facilitate methylation of retrotransposons (8). Both the establishment and maintenance of DNA methylation patterns are critical for development as mice deficient in DNMT3B or DNMT1 are embryonic lethal and DNMT3A-null mice die by 4 weeks of age (9). In normal cells, DNA methylation occurs predominantly in repetitive genomic regions, including satellite DNA and parasitic elements such as long interspersed transposable elements (LINEs) and short interspersed transposable elements (SINEs), maintaining genomic integrity (10). Methylated cytosines account for approximately $1 \%$ of total nucleotides and about $75 \%$ of all $\mathrm{CpG}$ dinucleotides in the human genome. The $\mathrm{CpG}$ dinucleotides are unevenly distributed across the human genome, but are concentrated in dense pockets called CpG islands (CGIs). About $50-60 \%$ of gene promoters lie within $\mathrm{CpG}$ islands, and it is estimated that the human genome contains approximately 29,000 CpG sequences (11). CpG islands particularly those associated with promoters are generally unmethylated in normal cells, providing access to transcription factors and chromatin-associated proteins for the expression of most housekeeping genes and several other regulated genes although some of them $(\sim 6 \%)$ become methylated in a tissue-specific manner during early development or in differentiated tissues $(4,12)$. DNA methylation can inhibit gene expression directly, by inhibiting the binding of specific transcription factors, and indirectly, by recruiting methyl-CpG-binding domain (MBD) proteins. The associated MBD family members in turn recruit histone-modifying and chromatin-remodeling complexes to methylated sites (13). To date, six methyl-CpG-binding proteins, including methylcytosine binding protein 2 (MECP2), MBD1, MBD2, MBD3, MBD4 and Kaiso, have been identified in mammals. MECP2 binds methylated DNA in vitro and in vivo. It contains a MBD at its amino terminus and a transcription repression domain (TRD) in the middle (13). Furthermore, it has been shown that nucleosome remodeling complex (NuRD) can methylate DNA by interacting with DNA methylation binding protein MBD2, which directs the NuRD complex to methylate DNA $(14,15)$. These and other recent findings have established that DNA cytosine methylation is a critical component of epigenetic gene regulation. A list of DNA methylation genes disrupted in various human cancers is shown in Table 1.

\section{Histone modification}

Histone modifications influence chromatin structure which plays an important role in gene regulation and carcinogenesis (16). Chromatin is a highly ordered structure consisting of repeats of nucleosomes connected by linker DNA. Each nucleosome encompasses $~ 146 \mathrm{bp}$ of DNA wrapped around an octamer of histone proteins. These octamers consist of two subunits of each of the following core histone proteins: H2A, H2B, H3 and H4 (17). Chromatin consists of DNA, histones, and non-histone proteins condensed into nucleoprotein complexes and functions as the physiological template of all eukaryotic genetic information (18). Histones are small basic proteins containing a globular domain and a flexible charged $\mathrm{NH}_{2}$ terminus known as the histone tail, which protrudes from the 
nucleosome. Regulation of gene expression occurs through posttranslational modifications of the histone tails provided by covalent modifications including acetylation, methylation, phosphorylation, ubiquitination, sumoylation, proline isomerization, and ADP ribosylation (19-21). Posttranslational modifications to histone tails govern the structural status of chromatin and the resulting transcriptional status of genes within a particular locus. These modifications are reversible and are controlled by a group of enzymes including histone acetyltransferases (HATs) and deacetylases (HDACs), methyltransferases (HMTs) and demethylases (HDMs), kinases, phosphatases, ubiquitin ligases and deubiquitinases, SUMO ligases and proteases which add and remove such modifications $(20,22)$. Chromatin is divided into two distinct conformation states: heterochromatin, which is densely compacted and transcriptionally inert and euchromatin, which is decondensed and transcriptionally active $(17,23)$. Euchromatin is characterized by high levels of acetylation and trimethylated $\mathrm{H} 3 \mathrm{~K} 4, \mathrm{H} 3 \mathrm{~K} 36$ and H3K79. On the other hand, heterochromatin is characterized by low levels of acetylation and high levels of H3K9, H3K27 and H4K20 methylation $(12,24,25)$. Studies have shown that histone modification levels are predictive for gene expression. Actively transcribed genes are characterized by high levels of H3K4me3, H3K27ac, $\mathrm{H} 2 \mathrm{BK} 5$-azacytidine (H2BK5ac) and H4K20me1 in the promoter and H3K79me1 and H4K20me1 along the gene body (26). Genome-wide studies have revealed that various combinations of histone modifications in a specific genomic region can lead to a more 'open' or 'closed' chromatin structure resulting in the activation or repression of gene expression $(12,24,25)$. A list of the histone-modifying genes altered during carcinogenesis is presented in Table 2 .

\section{Noncoding RNAs}

MicroRNAs (miRNAs) are small ncRNAs of $~ 22$ nucleotides and are involved in posttranslational gene silencing by controlling mRNA translation into proteins (27). miRNAs induce heritable changes in gene expression without altering DNA sequence and thus contribute to the epigenetic landscape. In addition, miR-NAs can both regulate and be regulated by other epigenetic mechanisms (28). Although miRNA are vital to normal cell physiology their mis-expression has been linked to several diseases, including cancer (4). Cancer development and miRNA profiles are now being used to classify human cancers (23, 28, 27). Approximately, 1000 miRNA genes have been computationally predicted in the human genome with each miRNA targeting multiple protein-coding transcripts. It has been predicted that miRNAs regulate the translation rate of more than $60 \%$ of protein-coding genes (7), and participate in the regulation of cellular processes. Like mRNAs, miRNAs are mainly transcribed by RNA polymerase-II although miRNA synthesis is known to occur by RNA polymerase-III in those miRNAs that reside near tRNA, Alu and mammalian-wide interspersed sequences (28). The first identified miRNAs, the products of the Caenorhabditis elegans genes lin-4 and let-7, have important roles in controlling developmental timing and probably act by regulating mRNA translation. When lin-4 or let-7 is inactivated, specific epithelial cells undergo additional cell divisions instead of their normal differentiation (27). A list of miRNAs dysregulated in cancer is presented in Table 3.

\section{Epigenetic modifications in cancer}

In human cancers, aberrant epigenomics are known to contribute to various phases of neoplastic development including initiation, promotion, invasion, metastases and chemotherapy resistance. It has been proposed recently that more than 300 genes and gene products are epigenetically altered in various human cancers (4). A link between DNA methylation and cancer was first shown in 1983, when it was shown that the genomes of cancer cells are hypomethylated relative to their normal counterparts (29). In terms of DNA methylation, cancer cells show genome-wide hypomethylation and site-specific CpG island promoter hypermethylation $(30,31)$. Hypermethylation at specific genes typically affects 
promoter CpG-islands inactivating transcription. Hypermethylation is observed at specific $\mathrm{CpG}$ islands. The transcriptional inactivation caused by promoter hypermethylation affects genes involved in the main cellular pathways: DNA repair [ $h M L H 1$ (mismatch repair gene 1), $M G M T$ (O6-methylguanine-DNA methyltransferase), WRN(Werner syndrome, RecQ helikase like), BRCA1 (breast cancer 1)], cell cycle control ( $\left.p 16^{I N K 4 a}, p 15^{I N K 4 b}, R B\right)$, Ras signaling $\{R A S S F 1 A$ [Ras association (RalGDS/AF-6) domain family member 1], NOREIA], apoptosis [TMS1 (target of methylation-induced silencing 1), DAPK1 (deathassociated protein kinase), $W I F-1, S F R P 1$ ], metastasis [cadherin 1 (CDH1), $C D H 13$, $P C D H 10$ ], detoxification [GSTP1 (glutathione S-transferase pi 1)], hormone response ( $E S R$ 1, ESR2), vitamin response [ $R A R B 2$ (retinoic acid receptor b2), $C R B P 1]$ and p53 network [ $p 14^{A R F}, p 73$ (also known as TP73), HIC-1] among others. This provides tumor cells with a growth advantage and increases their genetic instability and aggressiveness (22, 30). Hypomethylation in tumor cells is primarily caused by the loss of methylation from repetitive regions of the genome and the resulting genomic instability is a hallmark of tumor cells. In addition, imprinting patterns are often disturbed (32). In cancers, hypomethylation is often associated with oncogenes. c-Myc, a transcription factor that acts as an oncogene, is one of the widely reported hypomethylated genes in cancers. Hypomethylation at specific promoters can activate the aberrant expression of oncogenes and induce loss of imprinting (LOI). The most common LOI event due to hypomethy-lation is insulin-like growth factor 2 (IGF2), which has been reported in a wide range of tumor types, including breast, liver, lung and colon cancer $(33,34) . S 100 P$ in pancreatic cancer, $S N C G$ in breast and ovarian cancers and melanoma-associated gene (MAGE) and dipeptidyl peptidase $6(D P P 6)$ in melanomas are well-studied examples of hypomethylated genes in cancer $(12,35)$.

In addition to changes in DNA methylation, histone modification patterns are also altered in human tumors. Recent studies have shown that histone modification levels are predictive for gene expression. Actively transcribed genes are characterized by high levels of $\mathrm{H} 3 \mathrm{~K} 4 \mathrm{me} 3$, $\mathrm{H} 3 \mathrm{~K} 27 \mathrm{ac}, \mathrm{H} 2 \mathrm{BK} 5 \mathrm{ac}$ and H4K20me1 in the promoter and H3K79me1 and H4K20me1 along the gene body (26). Loss of acetylation is mediated by HDACs that have been found to be over-expressed or mutated in different tumor types. Aberrant expression of both HMTs and HDMs are observed in various cancer types (36). A recent study has described inactivating mutations in the histone methyltransferase SETD2 and in the histone demethylase UTX and $J A R I D 1 C$ in renal carcinomas $(36,37)$. $\mathrm{H} 3$ acetylation and $\mathrm{H} 3 \mathrm{~K} 9$ dimethylation can discriminate between cancerous and nonmalignant prostate tissue and $\mathrm{H} 3 \mathrm{~K} 4$ trimethylation can predict occurrence of prostate-specific antigen serum level elevation after prostatectomy for cancer (28). $E Z H 2$ (enhancer of zeste homolog 2) expression is an independent prognostic marker that is correlated with the aggressiveness of prostate, breast and endometrial cancers (38).

Because abnormal cell proliferation is a hallmark of human cancers, it seems possible that miRNA expression patterns might denote the malignant state. Indeed, altered expression of a few miRNAs has been found in some tumor types $(39,40)$. The first association between miRNA and cancer development was described in chronic lymphocytic leukemia with chromosome 13q14 deletion. This deletion deregulates miRNA-15 and miRNA-16 (41). Most of the targets of these two miRNAs are involved in cell growth and cell cycle. The let-7 is one of the most widely studied miRNA families in cancer. Alterations of let-7 function have been described in several human cancer types, including carcinomas of the head and neck region, lung, colon, rectum and ovary. It acts mainly as a tumor-suppressor miRNA (28). miRNA-145 is a well-known tumor-suppressor miRNA downregulated in many human cancers owing to aberrant DNA methylation of its promoter and/or p53 mutations (42). This miRNA is a pluripotency repressor which regulates silencing of $O C T$, SOX 2 and KLF4 in human embryonic stem cells; these genes are required for cell selfrenewal and pluripotency maintenance (43). Interestingly, it is becoming apparent that the 
expression of epigenetic regulatory enzymes such as DNMT, HATs, and HMTs can be controlled by miRNAs (44). In particular, the miRNA-29 family can directly regulate the expression of DNMTs such that downregulation of this family of miRNAs in small-cell lung cancer results in increased expression of DNMT3A and 3B causing a global genomic hypermethylation and specific methylation-induced silencing of tumor-suppressor genes such as FHIT and WWOX $(45,46)$.

\section{Influence of epigenetics on cancer genetics}

It is evident that discrete genetic alterations in neoplastic cells alone cannot explain multistep carcinogenesis whereby tumor cells are able to express diverse phenotypes during the complex phases of tumor development and progression. In fact, cancer cells have an altered epigenome compared to the tissues from which they arise. Deregulated epigenetic mechanisms may initiate genetic instability, resulting in the acquisition of genetic mutations in tumor-suppressor genes and activating genetic mutations in oncogenes. Moreover, epigenetic disruptions in tumors are generally of a clonal nature, indicating occurrence in early generations of cells (47). It is well known that 5-methylcytosine (m5C) residues are 'hot spots' for mutations, which can destabilize gene structure and function. One-third of germ-line point mutations leading to human genetic diseases occur at $\mathrm{CpGs}$ and most of these mutations are $\mathrm{C} \rightarrow \mathrm{T}$ transitions (48). This is because $\mathrm{m} 5 \mathrm{C}$ is highly mutable by deamination, resulting in transitional mutations (i.e. $\mathrm{C} \rightarrow \mathrm{T}$ ) at $\mathrm{CpGs}$. In view of the symmetry of these $\mathrm{CpG}$ motifs, the methylcytosine on the opposite strand may also be affected, leading to $(\mathrm{G} \rightarrow \mathrm{A})$ changes. As a consequence, $\mathrm{CpGs}$ are hot spots for mutations, in a variety of genes. $(48,49) \mathrm{G} \rightarrow \mathrm{A}$ transitions are found in $44.8 \%$ cases of leukemia and myelodysplasia, and in $60 \%$ of colon cancer cases. $\mathrm{C} \rightarrow \mathrm{T}$ and tandem CC-TT mutations are found in basal cell and squamous cell carcinomas (50). Methylation increases the rate of hydrolytic deamination and also increases the reactivity of neighboring guanines to electrophiles $(50,51)$. The oxidation of $\mathrm{m} 5 \mathrm{C}$ may contribute to the high frequency of $\mathrm{C} \rightarrow \mathrm{T}$ transitions at $\mathrm{CpG}$ sequences. Oxygen radicals can react with $\mathrm{m} 5 \mathrm{C}$ to oxidize the 5, 6-double bond; the intermediate product, $\mathrm{m} 5 \mathrm{C}$ glycol, then deaminates to form thymine glycol (52, 53). Oxidative stress can contribute to tumor development not only through genetic but also through epigenetic mechanisms. As noted earlier, the presence of hydroxyl radicals can cause a wide range of DNA lesions including base modifications, deletions, strand breakage and chromosomal rearrangements. Such DNA lesions have been shown to interfere with the ability of DNA to function as a substrate for the DNMTs, resulting in global hypomethylation (54). The presence of 8-OHdG in $\mathrm{CpG}$ dinucleotide sequences has been shown to strongly inhibit methylation of adjacent cytosine residues $(55,56)$. In addition, 8 OHdG may not be recognized by proof-reading enzymes and thus may persist as a mutation resulting in $\mathrm{G} \rightarrow \mathrm{T}$ transversions $(57,58)$. These studies suggest that oxidative DNA damage can affect patterns of DNA methylation leading to aberrant gene expression and possibly contributing to the development of malignancy.

\section{Hereditary cancer genes and cancer predisposition}

Studies of familial cancer have identified a group of genes whose mutational inactivation results in predisposition to a characteristic spectrum of cancers. The tumor-suppressor gene, $R B$ which is mutated in retinoblastoma, was the first hereditary cancer gene to be identified. Subsequently, other tumor-suppressor genes operating through a diverse range of mechanisms were identified in other familial cancers, e.g. adenomatosis polyposis coli $(A P C)$ mutations were identified in cases of familial adenomatous polyposis coli and p16 ${ }^{I N K 4 a}$ mutations were identified in cases of familial melanoma (59). DNA repair genes such as the $B R C A 1, M L H 1$, and $M S H 2$ are also often involved in predisposition to familial cancer $(60,61)$. Specific allele sequence variants such as single nucleotide polymorphisms (SNPs) affect the probability of CpG islands methylation in the cis region. Cis-acting DNA 
mutations have been shown to cause constitutional epi-mutations early in cancer development (62). One example of epigenetic silencing caused by sequence alterations in cis is the methylation of expanded CGG repeats within the FMR1 promoter in the fragile $\mathrm{X}$ mental retardation syndrome (63). Little is known about what causes variation in methylation levels and how this variation relates to future pathogenesis. Genetic factors may play key roles in maintaining a normal methylation pattern, but environmental factors also play an important role. Polymorphisms in MTHFR, DNMT3b, and MTR genes, involved in methyl metabolism or DNA methylation, are some of the obvious genetic candidates for variation in methylation in both normal and tumor tissues (64).

\section{Epigenetic biomarkers}

Methylated DNA sequences represent potential bio-markers for diagnosis, staging, prediction of prognosis and monitoring of response to therapy. Epigenetic markers can be evaluated in resected tumors or in body fluids (65). For example, the frequency of occurrence of hypermethylated CDH13, MYOD1, MGMT, p16 ${ }^{I N K 4 a}$ and RASSF1A genes varies significantly among cancer types. These changes can be detected in plasma DNA and urine. Recently, combined hypermethylation assays for small number of genes such as RASSF1A, RAR $2, A P C$ and GSTP1 have been used to discriminate between benign and cancerous changes in the prostate $(66,67)$. Furthermore, repetitive DNA elements such as SINEs and LINEs and other repetitive sequences are often hypomethylated. Their presence has been used to characterize some human cancers, but their clinical utility remains questionable (68).

Histone modification patterns also provide prognostic and diagnostic information in cancer. Repressive chromatin structures characterized by particular histone modifications such as H3K9, H3K27 and H4K20 methylation may precipitate DNA methylation. Generalized changes in chromatin structure and histone modification, such as increased H3K4 dimethylation and $\mathrm{H} 3 \mathrm{~K} 18$ acetylation activation, are associated with poor prognosis (69). Whether the extent of these changes correlates with alteration in gene activity is a major limitation.

More recently, miRNA has been proposed as potential epigenetic biomarkers in the diagnosis of cancer. Some of the miRNA such as miR-199a, miR-200a, miR-146, miR-214, miR-221 and miR-222 have been found to be upregulated, whereas miR-100 is downregulated in human cancers (44). The miRNA let-71 has been recently designated as a tumor-suppressor and miR-429, miR-200a and miR-200b were found to be clustered on a single primary transcript regulated by the epithelial-to-mesenchymal transition (70). Studies have shown that two other miRNAs, miR-21 and miR-181a can be used to identify the presence or absence of a malignant phenotype. A group of 27 miRNA has been shown to be significantly associated with chemotherapy response and proposed as possible prognostic and diagnostic biomarker $(71,72)$.

\section{Conclusions}

The epigenetic modification patterns associated with the development and progression of cancer are potentially clinically useful. The development of DNA methylation markers may prove useful for early cancer detection, establishing a diagnosis of cancer, or predicting the prognosis in cancer cases. Recent advances in epigenomic approaches allow mapping of the methylation/acetylation state and miRNA levels in the genome with high accuracy, which may help in the identification of biomarkers for various diseases. Understanding the molecular events that initiate and maintain epigenetic gene silencing could lead to the development of clinical strategies for the prevention and therapy of cancer. 


\section{Acknowledgments}

The reference from author's laboratory listed in this review was supported by United States Public Health Service Grants RO1 CA115491 and R21 CA109424. We apologize to those investigators whose original work could not be cited owing to the space limitations.

\section{References}

1. Berger SL, Kouzarides T, Shiekhattar R, et al. An operational definition of epigenetics. Genes Dev. 2009; 23:781-783. [PubMed: 19339683]

2. Rodenhiser D, Mann M. Epigenetics and human disease: translating basic biology into clinical applications. CMAJ. 2006; 174:341-348. [PubMed: 16446478]

3. Ducasse M, Brown MA. Epigenetic aberrations and cancer. Mol Cancer. 2006; 5:60. [PubMed: 17092350]

4. Kanwal R, Gupta S. Epigenetics and cancer. J Appl Physiol. 2010; 109:598-605. [PubMed: 20203073]

5. Wu SC, Zhang Y. Active DNA demethylation: many roads lead to Rome. Nat Rev Mol Cell Biol. 2010; 11:607-620. [PubMed: 20683471]

6. Rodriguez-Paredes M, Esteller M. Cancer epigenetics reaches mainstream oncology. Nat Med. 2011; 17:330-339. [PubMed: 21386836]

7. Burge CB, Friedman RC, Farh KKH, et al. Most mammalian mRNAs are conserved targets of microRNAs. Genome Res. 2009; 19:92-105. [PubMed: 18955434]

8. Fuks F, Deplus R, Brenner C, et al. Dnmt3L is a transcriptional repressor that recruits histone deacetylase. Nucleic Acids Res. 2002; 30:3831-3838. [PubMed: 12202768]

9. Li E, Okano M, Bell DW, et al. DNA methyltransferases Dnmt3a and Dnmt3b are essential for de novo methylation and mammalian development. Cell. 1999; 99:247-257. [PubMed: 10555141]

10. Robertson KD. DNA methylation and human disease. Nat Rev Genet. 2005; 6:597-610. [PubMed: 16136652]

11. Pradhan S, Kim JK, Samaranayake M. Epigenetic mechanisms in mammals. Cell Mol Life Sci. 2009; 66:596-612. [PubMed: 18985277]

12. Esteller M, Portela A. Epigenetic modifications and human disease. Nat Biotechnol. 2010; 28:1057-1068. [PubMed: 20944598]

13. Bogdanovic O, Veenstra GJ. DNA methylation and methyl-CpG binding proteins: developmental requirements and function. Chromosoma. 2009; 118:549-565. [PubMed: 19506892]

14. Dehan P, Kustermans G, Guenin S, et al. DNA methylation and cancer diagnosis: new methods and applications. Expert Rev Mol Diagn. 2009; 9:651-657. [PubMed: 19817550]

15. Lai AY, Wade PA. Cancer biology and NuRD: a multifaceted chromatin remodelling complex. Nat Rev Cancer. 2011; 11:588-596. [PubMed: 21734722]

16. Cedar H, Bergman Y. Linking DNA methylation and histone modification: patterns and paradigms. Nat Rev Genet. 2009; 10:295-304. [PubMed: 19308066]

17. Johnstone RW, Bots M. Rational combinations using HDAC inhibitors. Clin Cancer Res. 2009; 15:3970-3977. [PubMed: 19509171]

18. Suganuma T, Workman JL. Signals and combinatorial functions of histone modifications. Annu Rev Biochem. 2011; 80:473-499. [PubMed: 21529160]

19. Cohen I, Poreba E, Kamieniarz K, et al. Histone modifiers in cancer: friends or foes? Genes Cancer. 2011; 2:631-647. [PubMed: 21941619]

20. Kouzarides T. Chromatin modifications and their function. Cell. 2007; 128:693-705. [PubMed: 17320507]

21. Bannister AJ, Kouzarides T. Regulation of chromatin by histone modifications. Cell Res. 2011; 21:381-395. [PubMed: 21321607]

22. Esteller M. Epigenetic gene silencing in cancer: the DNA hypermethylome. Hum Mol Genet. 2007; 16 (Spec1):R50-R59. [PubMed: 17613547] 
23. Iorio MV, Piovan C, Croce CM. Interplay between microRNAs and the epigenetic machinery: an intricate network. Biochem Biophys Acta. 2010; 1799:694-701. [PubMed: 20493980]

24. Li B, Carey M, Workman JL. The role of chromatin during transcription. Cell. 2007; 128:707-719. [PubMed: 17320508]

25. Izzo A, Schneider R. Chatting histone modifications in mammals. Brief Funct Genomics. 2010; 9:429-443. [PubMed: 21266346]

26. Karlic R, Chung HR, Lasserre J, et al. Histone modification levels are predictive for gene expression. Proc Natl Acad Sci U S A. 2010; 107:2926-2931. [PubMed: 20133639]

27. Golub TR, Lu J, Getz G, et al. MicroRNA expression profiles classify human cancers. Nature. 2005; 435:834-838. [PubMed: 15944708]

28. Lopez-Serra P, Esteller M. DNA methylation-associated silencing of tumor-suppressor microRNAs in cancer. Oncogene. 2011; 16:1-14.

29. Bruserud O, Stapnes C, Ersvaer E, et al. Histone deacetylase inhibitors in cancer treatment: a review of the clinical toxicity and the modulation of gene expression in cancer cell. Curr Pharm Biotechnol. 2007; 8:388-400. [PubMed: 18289048]

30. Shen L, Kondo Y, Guo Y, et al. Genome-wide profiling of DNA methylation reveals a class of normally methylated CpG island promoters. PLoS Genet. 2007; 3:2023-2036. [PubMed: 17967063]

31. Sincic N, Herceg Z. DNA methylation and cancer: ghosts and angels above the genes. Curr Opin Oncol. 2011; 23:69-76. [PubMed: 21119515]

32. Markowitz SD, Li M, Chen WD, et al. Sensitive digital quantification of DNA methylation in clinical samples. Nat Biotechnol. 2009; 27:858-U118. [PubMed: 19684580]

33. Chan WY, Cheung HH, Lee TL, et al. DNA methylation of cancer genome. Birth Defects Res C. 2009; 87:335-50.

34. Cui HM. Loss of imprinting of IGF2 as an epigenetic marker for the risk of human cancer. Dis Markers. 2007; 23:105-112. [PubMed: 17325430]

35. Sadikovic B, Al-Romaih K, Squire JA, et al. Cause and consequences of genetic and epigenetic alterations in human cancer. Curr Genomics. 2008; 9:394-408. [PubMed: 19506729]

36. Allis CD, Chi P, Wang GG. Covalent histone modifications - miswrit-ten, misinterpreted and miserased in human cancers. Nat Rev Cancer. 2010; 10:457-469. [PubMed: 20574448]

37. Teh B, Dalgliesh GL, Furge K, et al. Systematic sequencing of renal carcinoma reveals inactivation of histone modifying genes. Nature. 2010; 463:360-363. [PubMed: 20054297]

38. Akslen LA, Bachmann IM, Halvorsen OJ, et al. EZH2 expression is associated with high proliferation rate and aggressive tumor subgroups in cutaneous melanoma and cancers of the endometrium, prostate, and breast. J Clin Oncol. 2006; 24:268-273. [PubMed: 16330673]

39. Michael MZ, O'Connor SM, Pellekaan NGV, et al. Reduced accumulation of specific microRNAs in colorectal neoplasia. Mol Cancer Res. 2003; 1:882-891. [PubMed: 14573789]

40. Olson P, Lu J, Zhang H, et al. MicroRNA dynamics in the stages of tumorigenesis correlate with hallmark capabilities of cancer. Genes Dev. 2009; 23:2152-2165. [PubMed: 19759263]

41. Calin GA, Dumitru CD, Shimizu M, et al. Frequent deletions and down-regulation of micro-RNA genes miR15 and miR16 at 13q14 in chronic lymphocytic leukemia. Proc Natl Acad Sci U S A. 2002; 99:15524-1529. [PubMed: 12434020]

42. Dahiya R, Suh SO, Chen Y, et al. MicroRNA-145 is regulated by DNA methylation and p53 gene mutation in prostate cancer. Carcinogenesis. 2011; 32:772-778. [PubMed: 21349819]

43. Kosik KS, Xu N, Papagiannakopoulos T, et al. MicroRNA-145 Regulates OCT4, SOX2, and KLF4 and Represses Pluripotency in Human Embryonic Stem Cells. Cell. 2009; 137:647-658. [PubMed: 19409607]

44. Esteller M, Guil S. DNA methylomes, histone codes and miRNAs: tying it all together. Int J Biochem Cell. 2009; B41:87-95.

45. Croce CM, Fabbri M, Garzon R, et al. MicroRNA-29 family reverts aberrant methylation in lung cancer by targeting DNA methyl-transferases 3A and 3B. Proc Natl Acad Sci U S A. 2007; 104:15805-15810. [PubMed: 17890317] 
46. Denis H, Ndlovu MN, Fuks F. Regulation of mammalian DNA methyl-transferases: a route to new mechanisms. EMBO Rep. 2011; 12:647-656. [PubMed: 21660058]

47. Ellis L, Atadja PW, Johnstone RW. Epigenetics in cancer: targeting chromatin modifications. Mol Cancer Ther. 2009; 8:1409-1420. [PubMed: 19509247]

48. Lee DH, O'Connor TR, Pfeifer GP. Oxidative DNA damage induced by copper and hydrogen peroxide promotes $\mathrm{CG}$-> TT tandem mutations at methylated $\mathrm{CpG}$ dinucleotides in nucleotide excision repair-deficient cells. Nucleic Acids Res. 2002; 30:3566-3573. [PubMed: 12177298]

49. Soussi T, Beroud C. Significance of TP53 mutations in human cancer: a critical analysis of mutations at CpG dinucleotides. Hum Mutat. 2003; 21:192-200. [PubMed: 12619105]

50. Parry TE. Mutagenic mechanisms in leukemia and cancer: a new concept - cytosine lack could be as mutagenic as cytosine deamination. Leuk Res. 2006; 30:1079-1083. [PubMed: 16820204]

51. Zuo SJ, Boorstein RJ, Teebor GW. Oxidative Damage to 5-Methyl-cytosine in DNA. Nucleic Acids Res. 1995; 23:3239-3243. [PubMed: 7667100]

52. Chen ZQ, Zhang CH, Kim C, et al. Quantum mechanics study and Monte Carlo simulation on the hydrolytic deamination of 5-methylcytosine glycol. Phys Chem Chem Phys. 2011; 13:6471-6483. [PubMed: 21380473]

53. Ziegel R, Shallop A, Upadhyaya P, et al. Endogenous 5-methylcytosine protects neighboring guanines from N7 and O6-methylation and O6-pyridyloxobutylation by the tobacco carcinogen 4(methylnitrosamino)-1-(3-pyridyl)-1-butanone. Biochemistry. 2004; 43:540-549. [PubMed: 14717610]

54. Donkena KV, Young CY, Tindall DJ. Oxidative stress and DNA methylation in prostate cancer. Obstet Gynecol Int. 2010:302051-1-14. [PubMed: 20671914]

55. Sowers LC, Valinluck V, Tsai HH, et al. Oxidative damage to methyl-CpG sequences inhibits the binding of the methyl-CpG binding domain (MBD) of methyl-CpG binding protein 2 (MeCP2). Nucleic Acids Res. 2004; 32:4100-4108. [PubMed: 15302911]

56. Maltseva DV, Baykov AA, Jeltsch A, et al. Impact of 7,8-dihydro-8-oxoguanine on methylation of the CpG site by Dnmt3a. Biochemistry. 2009; 48:1361-1368. [PubMed: 19161295]

57. Tudek B, Winczura A, Janik J. Involvement of oxidatively damaged DNA and repair in cancer development and aging. Am J Transl Res. 2010; 2:254-284. [PubMed: 20589166]

58. Franco R, Schoneveld O, Georgakilas AG, et al. Oxidative stress, DNA methylation and carcinogenesis. Cancer Lett. 2008; 266:6-11. [PubMed: 18372104]

59. Rahman N, Scott RH. Cancer genes associated with phenotypes in monoallelic and biallelic mutation carriers: new lessons from old players. Hum Mol Genet. 2007; 16 (Spec1):R60-R66. [PubMed: 17613548]

60. Stoger R, Kajimura TM, Brown WT, et al. Epigenetic variation illustrated by DNA methylation patterns of the fragile-X gene FMR1. Hum Mol Genet. 1997; 6:1791-1801. [PubMed: 9302255]

61. Bacolod MD, Schemmann GS, Giardina SF, et al. Emerging paradigms in cancer genetics: some important findings from high-density single nucleotide polymorphism array studies. Cancer Res. 2009; 69:723-727. [PubMed: 19155292]

62. Chen H, Taylor NP, Sotamaa KM, et al. Evidence for heritable predisposition to epigenetic silencing of MLH1. Int J Cancer. 2007; 120:1684-1688. [PubMed: 17230510]

63. Dobrovic A, Kristensen LS. Direct genotyping of single nucleotide polymorphisms in methyl metabolism genes using probe-free high-resolution melting analysis. Cancer Epidem Biomar. 2008; 17:1240-1247.

64. Herman JG, Esteller M, Garcia-Foncillas J, et al. Inactivation of the DNA-repair gene MGMT and the clinical response of gliomas to alkylating agents. New Engl J Med. 2000; 343:1350-1354. [PubMed: 11070098]

65. Lin HJL, Zuo T, Chao JR, et al. Seed in soil, with an epigenetic view. Biochem Biophys Acta. 2009; 1790:920-924. [PubMed: 19162126]

66. Lyko F, Brown R. DNA methyltransferase inhibitors and the development of epigenetic cancer therapies. J Natl Cancer Inst. 2005; 97:1498-1506. [PubMed: 16234563]

67. McCabe MT, Brandes JC, Vertino PM. Cancer DNA methylation: molecular mechanisms and clinical implications. Clin Cancer Res. 2009; 15:3927-3937. [PubMed: 19509173] 
68. Metias SM, Lianidou E, Yousef GM. MicroRNAs in clinical oncology: at the crossroads between promises and problems. J Clin Pathol. 2009; 62:771-776. [PubMed: 19734473]

69. Myzak MC, Dashwood RH. Histone deacetylases as targets for dietary cancer preventive agents: lessons learned with butyrate, diallyl disulfide, and sulforaphane. Curr Drug Targets. 2006; 7:443452. [PubMed: 16611031]

70. Pandey M, Shukla S, Gupta S. Promoter demethylation and chromatin remodeling by green tea polyphenols leads to re-expression of GSTP1 in human prostate cancer cells. Int J Cancer. 2010; 126:2520-2533. [PubMed: 19856314]

71. Paranjape T, Slack FJ, Weidhaas JB. MicroRNAs: tools for cancer diagnostics. Gut. 2009; 58:1546-5154. [PubMed: 19834118]

72. Peter ME. Let-7 and miR-200 microRNAs Guardians against pluripotency and cancer progression. Cell Cycle. 2009; 8:843-852. [PubMed: 19221491] 
Table 1

DNA methylation gene changes in various human cancers

\begin{tabular}{|c|c|c|c|}
\hline DNA methyltransferase & Function & Alterations & Cancer type \\
\hline DNMT 1 & $\begin{array}{l}\text { Maintenance of methylation, repression of } \\
\text { transcription }\end{array}$ & Upregulation, mutation & Colorectal cancer, ovarian cancer \\
\hline DNMT3a & $\begin{array}{l}\text { De novo methylation during embryogenesis, } \\
\text { imprint establishment, repression }\end{array}$ & Upregulation & $\begin{array}{l}\text { Colorectal cancer, breast cancer, } \\
\text { ovarian cancer, esophageal squamous } \\
\text { cell carcinoma }\end{array}$ \\
\hline DNMT3b & $\begin{array}{l}\text { De novo methylation during embryogenesis, } \\
\text { repeat methylation repression }\end{array}$ & Upregulation & $\begin{array}{l}\text { Breast cancer, hepatocellular } \\
\text { carcinoma, colorectal cancer, }\end{array}$ \\
\hline DNMT3L & $\begin{array}{l}\text { Interacts with DNMT3a \&b and facilitate } \\
\text { methylation }\end{array}$ & Upregulation & \\
\hline \multicolumn{4}{|c|}{ Methyl-CpG- binding proteins } \\
\hline $\mathrm{MeCP} 2$ & Transcription repression & Upregulation, Mutation & Prostate cancer, Rett syndrome, \\
\hline MBD1 & Transcription repression & Upregulation, Mutation & $\begin{array}{l}\text { Prostate cancer, colon cancer, lung } \\
\text { cancer }\end{array}$ \\
\hline MBD2 & Transcription repression & Upregulation, Mutation & $\begin{array}{l}\text { Prostate cancer, colon cancer, lung } \\
\text { cancer }\end{array}$ \\
\hline MBD3 & Transcription repression & Upregulation, Mutation & Colon cancer, lung cancer \\
\hline MBD4 & $\begin{array}{l}\text { DNA repair, glycosylase domain, repair of } \\
\text { deaminated 5-methylC }\end{array}$ & Upregulation, Mutation & $\begin{array}{l}\text { Colon cancer, gastric cancer, } \\
\text { endometrial cancer }\end{array}$ \\
\hline Kaiso & Transcription repression & Upregulation & Colon, intestinal, lung cancer \\
\hline
\end{tabular}

DNMT, DNA methyltransferase; MBD, methyl-CpG-binding domain. 
Table 2

Histone modification genes altered in various human cancers

\begin{tabular}{|c|c|c|}
\hline Histone deacetylases & Alterations & Cancer type \\
\hline HDAC1 & Upregulation/Downregulation & $\begin{array}{l}\text { Colorectal cancer, cervical dysplasias, endometrial stromal sarcomas, } \\
\text { gastric carcinomas, colon cancer }\end{array}$ \\
\hline HDAC2 & Upregulation/Mutation & Multiple gastric carcinomas, colon cancer \\
\hline HDAC3 & Upregulation & Colon cancer \\
\hline HDAC4 & Upregulation/Downregulation /Mutation & Prostate, breast and colon cancer \\
\hline HDAC5 & Under expression & Colon cancer, AML \\
\hline HDAC6 & Upregulation & Breast, AML \\
\hline HDAC7 & Upregulation & Colon cancer \\
\hline HDAC8 & Upregulation & Colon cancer \\
\hline SIRT1 & Upregulation/Downregulation & Colon cancer \\
\hline SIRT2 & Downregulation, Deletion & Glioma \\
\hline SIRT3 & Upregulation & Breast cancer \\
\hline SIRT4 & Downregulation & AML \\
\hline SIRT7 & Upregulation & Breast, thyroid carcinoma \\
\hline \multicolumn{3}{|c|}{ Histone acetyl transferases } \\
\hline P300 & Mutation, Translocation, Deletions & Colorectal, breast, ovarian, hepatocellular and oral carcinomas, \\
\hline СBP & Mutation, Translocation, Deletions & Colon, breast, ovarian and AML \\
\hline PCAF & Mutation & Colon \\
\hline $\mathrm{MOZ}$ & Translocation & Hematologic malignancy \\
\hline MORF & Translocation & Hematologic, uterine leiomyomata \\
\hline Tip60 & Downregulation, translocation & Colorectal, prostate cancer \\
\hline GCN5 & Downregulation, mutation & Prostate, breast ovary \\
\hline PCAF & Rare mutation & Colon cancer \\
\hline HBO1 & Upregulation & Testis, breast, ovary and bladder cancer \\
\hline \multicolumn{3}{|c|}{ Histone methyltransferase } \\
\hline MLL1 & Translocation, Amplification & Hematologic malignancies \\
\hline MLL2 & Amplification & Glioma, pancreatic cancer \\
\hline MLL3 & Mutation, Deletion & Hematologic malignancies, colon cancer \\
\hline MLL4 & Amplification & Solid tumor \\
\hline SUV39H1-2 & Mutation overexpression & Ovarian, colon \\
\hline G9a & Gene Repression & Colon, gastric, breast cancer \\
\hline RIZ1/ PRDM2 & Underexpression, Mutations & Colorectal, gastric cancer \\
\hline EVI1 & Chromosomal rearrangement & Myeloid leukemia \\
\hline EZH2 & Amplification, Upregulation & Prostate, breast ovarian cancer \\
\hline SUZ12 & Upregulation & Prostate, breast ovarian cancer \\
\hline BMI1 & Upregulation & Prostate, breast ovarian cancer \\
\hline NSD1 & Translocation, Upregulation & AML \\
\hline NSD2 & Translocation & Multiple myeloma \\
\hline NSD2 & Translocation & Multiple myeloma \\
\hline NSD3 & Translocation, Amplification & AML, breast cancer \\
\hline
\end{tabular}




\begin{tabular}{lll}
\hline Histone deacetylases & Alterations & Cancer type \\
\hline SYMD2 & Upregulation & Breast, colon cancer \\
DOT1 & Upregulation & AML \\
Histone demethylases & & \\
LSD1/BHC110 & Downregulation & Breast cancer \\
JARID1A-D & Upregulation /Inactivation mutation & Leukemia, prostate, breast renal carcinoma \\
JHDM2a, 2b & Upregulation & T-cell lymphoma \\
JMJD2A/JHDM3A & Upregulation & Squamous cell carcinomas, lung cancer \\
JMJD3 & Downregulation & Lung, liver cancer \\
UTX & Inactivation mutation & Squamous cell carcinomas, renal cell carcinomas \\
\hline
\end{tabular}

CBP, CREB binding protein; Dot1, disruptor of telomeric silencing EZH2, enhancer of zest homolog2; Gcn5, general control nonderepressible; HBO1, histone acetyltransferase binding to ORC1; HDAC, histone deacetylase; JARID, Jumonji, AT-rich interactive-domain JHDM, JmjC domain-containing histone demethylase 1; JMJD, Jumonji domain containing 2; LSD1, lysine specific demethylase 1; MLL, myeloid/lymphoid or mixedlineage leukemia-associated protein; Morf, MOZ-related factors; MOZ, monocytic leukemia zinc finger protein; NSD1, nuclear receptorbinding SET-domain protein 1; p300, E1A binding protein p300; PCAF, p300/CBP-associated factor; PRMT, protein arginine methyltransferase 1; RIZ1, retinoblastoma protein-interacting zinc finger 1; SIRT, Sir2 histone deacetylase gene family; SMYD2, split SET/MYND domain-containing histone H3 lysine 36-specific methyltransferase; SUV39H, suppressor of variation 3-9 homolog; TIP60, human HIV-1 Tat interactive protein 60; UTX, ubiquitously transcribed tetratricopeptide repeat, X chromosome. 
Table 3

MicroRNAs alteration in various human cancers

\begin{tabular}{|c|c|c|c|}
\hline MicroRNAs & Target gene(s) & Alterations & Cancer type \\
\hline miR-127 & Bcl-6 & Upregulation & Bladder cancer \\
\hline $\operatorname{miR}-124$ & CDK6 & Upregulation & Colon cancer \\
\hline $\operatorname{miR}-223$ & NFI-A, MEF2C & Upregulation & Acute myeloid leukemia \\
\hline $\mathrm{miR}-34 \mathrm{~b} / 34 \mathrm{c}$ & p53 network, CDK6, E2F3 & Upregulation & Colon cancer \\
\hline miR-17, miR-92 & c-MYC & Upregulation & Lung cancer \\
\hline miR-372, miR-373 & RAS, p53,CD44 & Upregulation & $\begin{array}{l}\text { Testicular germ cell tumor and breast } \\
\text { cancer }\end{array}$ \\
\hline $\operatorname{miR}-21$ & $\begin{array}{l}\text { PDCD4, PTEN, TPM1, REC, TIMP3, } \\
\text { BCL2 }\end{array}$ & Upregulation & Glioblastoma, breast, lung, prostate, \\
\hline miR-155 & RHOA & Upregulation & $\begin{array}{l}\text { Burkitt's lymphoma, breast, colon, and } \\
\text { lung cancers }\end{array}$ \\
\hline miR-146 & $N F-\kappa B$ & Upregulation & Breast, pancreas and prostate cancers \\
\hline $\operatorname{miR}-92 b$ & PRMT5 & Upregulation & Brain primary tumors \\
\hline $\operatorname{miR}-520$ & $\mathrm{CD} 44$ & Upregulation & Breast cancer \\
\hline $\operatorname{miR}-10 b$ & HOXD10 & Upregulation & Metastatic breast cancer \\
\hline miR-9 & $\mathrm{CDH} 1$ & Upregulation & Breast cancer \\
\hline miR-127, miR-199a & BCL6, E2F1 & Upregulation & Cervical cancer \\
\hline $\operatorname{miR}-421$ & CBX7, RBMXL1 & Upregulation & Gastric cancer \\
\hline $\begin{array}{l}\text { miR-1228, miR-195, miR30b, } \\
\text { miR-32, miR345 }\end{array}$ & CDKN2A, NF2, and JUN & Upregulation & Malignant mesothelioma \\
\hline miR-190, miR-196 & HGF & Upregulation & Pancreatic cancer \\
\hline $\operatorname{miR}-125$ & $\begin{array}{l}\text { AKT, ERBB2-4, FGF, FGFR, IGF, } \\
\text { MAPKs, MMP11, SP1, TNF, VEGF }\end{array}$ & Upregulation & Breast cancer \\
\hline $\operatorname{miR}-29$ & DNMT3a\&b & Upregulation & Lung cancer \\
\hline miR-1 & FoxP1 & Upregulation & Hepatocarcinoma \\
\hline miR-9-3 & E-cadherin & Upregulation & $\begin{array}{l}\text { Colorectal, melanoma, head and neck } \\
\text { cancer }\end{array}$ \\
\hline $\operatorname{miR}-34 a$ & CD44, Notch1 & Upregulation & Hematological, prostate, breast cancer \\
\hline miR-181c & Notch4, K-Ras & Upregulation & Gastric, colorectal cancer \\
\hline miR-200c, miR-141, miR-429 & ZEB1/ZEB2 & Upregulation & Colorectal, breast, lung cancer \\
\hline miR-126 & CRK1, PIK3R2, SPRED1, VCAM1 & Downregulation & Breast and lung cancer \\
\hline miR-146a, miR-146b & ROCK1, IRAK1, TRAF6 & Downregulation & $\begin{array}{l}\text { Prostate cancer and papillary thyroid } \\
\text { carcinomas }\end{array}$ \\
\hline miR-340, miR-421, miR-658 & MYC, RB, PTEN & Downregulation & $\begin{array}{l}\text { Lymph node metastasis and gastric } \\
\text { cancer }\end{array}$ \\
\hline let-7a-3 & RAS, IGF-II & Downregulation & Lung and ovarian cancer \\
\hline miR-221, miR-222 & CDKN1C/P57 and CDKN1B/P27 & Downregulation & Hepatocellular carcinoma \\
\hline miR-9 & $N F-\kappa B$ & Downregulation & Ovarian and lung cancer \\
\hline miR-218, miR-145 & PXN & Downregulation & Breast, lung and prostate cancer \\
\hline miR-25, miR-32, miR-142 & ITGAa 1 & Downregulation & Lung cancer and solid tumor \\
\hline miR-124, miR-183 & ITGB $\beta 1$ & Downregulation & Lung cancer \\
\hline miR-143 & ERK5 & Downregulation & Cervical cancer \\
\hline miR-372, miR-373 & LATS2 & Downregulation & Testicular germ cell cancer \\
\hline
\end{tabular}




\begin{tabular}{llll}
\hline MicroRNAs & Target gene(s) & Alterations & Cancer type \\
\hline miR-181 & VGFR & Downregulation & Lung cancer \\
miR-370 & MAP3K8 & Downregulation & Cholangiocarcinoma \\
miR-342 & ER, PR and HER2 & Downregulation & Breast and colon cancer \\
miR-145 & ER & Downregulation & Colon and breast cancer \\
miR-124, miR-183 & ITGB1 $\beta$ & Downregulation & Lung cancer \\
miR-101 & EZH2 & Downregulation & Prostate, breast, Lung \\
miR-143 & DNMT3a & Downregulation & Colorectal cancer \\
miR-9-1 & FGF family & Downregulation & Breast, ovarian, pancreas cancer \\
miR-137 & CDK6, E2F6, LSD & Downregulation & Glioblastoma, oral, colorectal cancer \\
miR-129-2 & SOX4 & Downregulation & Gastric, endometrial, colorectal cancer \\
miR-145 & OCT/SOX2/KLF & Downregulation & Prostate cancer \\
miR-148 & TGIF2 & Downregulation & Colorectal, melanoma, head and neck \\
miR-199a & cancer \\
IKKB & Downregulation & Hepatocarcinoma, testicular ovarian \\
miR-203 & cancer \\
miR-205 & ABL1 & Downregulation & Hematological, liver cancer \\
miR-335 & ZEB1/ZEB2 & Downregulation & Bladder, breast, prostate cancer \\
miR-342 & SOX4/TNC & Downregulation & Breast cancer \\
\hline & PDGFRA & Downregulation & Ovarian, breast cancer \\
\hline & & & \\
& & &
\end{tabular}

BCL2, B-cell lymphoma 2 protein; CBX7, chromobox 7; CD44, cluster differentiation 44; CDH1, cadherin-1; CDK6, cyclin D kinase 6; CDNK2A, cyclin-dependent kinase inhibitor 2A; CRK1, Cdc2-related kinase1; ER, estrogen receptor; ERBB2-4 or (HER4), human epidermal growth factor receptor 4; ERK5, extracellular signal-regulated kinase 5; FGFR, fibroblast growth factor receptor; FOXP1, forkhead box protein O1; HGF, hepatocyte growth factor; HOXD10, homeobox D10; IGF-II, insulin-like growth factor 2; IRAK1, interleukin-1 receptor associated kinase-1; KLF, Kruppel-like factors; LATS2, large tumor-suppressor, homolog 2; MAPKs, mitogen-activated protein kinase; MEF2C, myocyte enhancer factor 2C; MMP11, matrix metalloproteinase11; NF2, neurofibromatosis, type 2; NFIA, nuclear factor 1 A-type; NF-kB, nuclear factorкB; OCT4, octamer-binding transcription factor 4; P53, tumor protein 53; PDcD4, programmed cell death 4; PDGFRA, alpha-type platelet-derived growth factor receptor; PIK3R2, Phosphatidylinositol 3-kinase regulatory subunit beta; PR, progesterone receptor; PRNT5, protein arginine $N$ methyltransferase 5; PTEN, phosphatase and tensin homolog; PXN, paxilin; ITG $\beta 1$, integrin beta-1; RAS, rat sarcoma; Rb, retinoblastoma; RBMX L1, RNA binding motif protein X-linked; RECK, reversion inducing cysteine rich protein kazal Motif; ROCK1, rho-associated, coiled-coil containing protein kinase 1; ROHA, Ras homolog gene family member A; SOX4, SRY (sex determining region Y)-box 4; SPRED1, sproutyrelated, EVH1 domain containing 1; TNFa, tumor necrosis factor-alpha; TPM1, tropomyosin 1; TRAF6, TNF receptor associated factor 6; VCAM, vascular cell adhesion molecule; VEGF, vascular endothelial growth factor; ZEB1, zinc finger E-box-binding homeobox 1. 